Resultant wordcount: 5527

\title{
Eco-efficiency trends of the Flemish industry: decoupling of environmental impact from economic growth
}

J. Van Caneghem ${ }^{\mathrm{a}^{*}}$, C. Block ${ }^{\mathrm{b}}$, H. Van Hooste ${ }^{\mathrm{c}}$, C. Vandecasteele ${ }^{\mathrm{a}}$

a Department of Chemical Engineering, Leuven University, W. Decroylaan 46, B3001 Leuven, Belgium

${ }^{\mathrm{b}}$ Groep T Leuven Engineering College, Vesaliusstraat 16, B-3000 Leuven, Belgium

cFlemish Environmental Agency - Division "Monitoring networks and research", Van Benedenlaan 34, B-2800 Mechelen, Belgium

Keywords: Eco-efficiency, industry, eco-indicators, Flanders, decoupling

\begin{abstract}
A methodology for eco-efficiency reporting is proposed with eco-efficiency indicators for climate change, acidification, photo-oxidant formation, human toxicity, freshwater aquatic ecotoxicity, eutrophication, energy consumption and waste generation. The method is applied to emission, consumption and production data of the Flemish industry provided by the Flemish environmental agency for the period 1995 to 2006. For climate change, acidification, photo-oxidant formation, human

\footnotetext{
${ }^{*}$ Corresponding author. Tel.: ++32 16322353, fax: ++3216322991. E-mail address: jo.vancaneghem@cit.kuleuven.be
} 
toxicity, freshwater aquatic ecotoxicity and eutrophication, the eco-efficiency improved by $39,55,41,58,72$ and $53 \%$, respectively. For each of these impact categories, the total environmental impact decreased despite an increase in production, indicating absolute decoupling of environmental impact from economic growth. The eco-efficiency indicator for energy consumption and waste generation improved by 16 and 14\%, respectively. However, due to the increase in production, the total energy consumption and the amount of waste generated increased: for these two environmental themes decoupling from economic growth was relative. Despite the improved eco-efficiency, industry remains one of the main polluters in Flanders. The application of the method to emission, energy consumption and production data of the Flemish industry resulted in a comprehensive and correct source of information for the general public and the government. Moreover, it can serve as a basis for economically and environmentally sound decisions and for the evaluation of the impact of former decisions.

\section{Introduction}

According to the World Business Council for Sustainable Development, ecoefficiency is "achieved by the delivery of competitively priced goods and services that satisfy human needs and bring quality of life, while progressively reducing ecological impacts and resource intensity throughout the life-cycle to a level at least in line with the earth's estimated carrying capacity" [1]. During the last decade, several methods were reported, with indicators for reporting and measuring eco- 
efficiency of companies and industrial regions $[1,2,3,4]$. The main objective of these methods is to provide information on environmental performance vis-à-vis economical performance in a comprehensive, systematic and consistent manner over periods of time [2]. Van Gerven et al. [5] and Block et al. [6] analysed 9 environmental indicators for the industrial sector by means of 6 criteria and ecoefficiency scored best, mainly because the methodology is already well investigated and data needed for calculation are readily available. Another term describing the relation between environmental impacts and the production of economic goods is “decoupling” [7]. Decoupling occurs where the environmental impact shows a decreasing trend or increases less than the economical performance. In this paper, a method for eco-efficiency reporting is proposed, including a maximum of environmental effects potentially caused by the considered emissions and consumptions. The method includes indicators for the environmental themes climate change, acidification, photo-oxidant formation, human toxicity, freshwater aquatic ecotoxicity and eutrophication, energy consumption and waste generation. Moreover it provides a way to comprehensively visualize the degree of decoupling. An extensive literature search revealed that, despite the numerous eco-efficiency indicators described, there is a lack of papers and reports in which the indicators are applied to realistic emission data and to realistic production or financial data.

Therefore this paper applies the proposed method to the emission, consumption and production data of the Flemish industry, which are annually collected by the Flemish Environmental Agency. These data are readily available [8] and reliable because they 
have been collected following the same method every year and because they are controlled by the Flemish government. In Flanders (the northern part of Belgium), industry is a sector of major economic importance: it accounts for 34\% of the Flemish export (out of Belgium), $27 \%$ of the Flemish turnover, $27 \%$ of the investments made in Flanders and employs 23\% of the Flemish labor force [8,9].

First the method for eco-efficiency reporting is proposed and the way the data for the Flemish industry were collected is described. Then, the method is applied to the data and for each environmental theme the total yearly industrial impact and the ecoefficiency indicator for the years 1995 to 2006 are graphically represented and discussed.

\section{Methods}

\subsection{Eco-efficiency indicators}

In the method developed and applied in this paper, the environmental impact of emissions to air and water of e.g. a production process, a company or an industrial sector is expressed by means of eco-efficiency indicators for the impact categories climate change, acidification, photo-oxidant formation, human toxicity, freshwater aquatic ecotoxicity and eutrophication. Each eco-efficiency indicator is defined as the environmental impact in the respective impact category divided by a suitable economic indicator. This economic indicator is selected taking into account the evaluated processes. It should be relevant, readily available and reliable. Examples are the yearly production volume e.g. in case only one production process is considered or the yearly turnover e.g. for a group of companies producing different 
products and services. The eco-efficiency indicators for energy consumption and waste generation are defined as the quantity of energy consumed and of waste generated, respectively, divided by the economic indicator.

This paper focuses on the application of the method to realistic emission data and on the interpretation of the results. It is not the aim to discuss the scientific background of the factors used to calculate environmental impacts. Paragraphs 2.1.1 and 2.1.2 therefore only briefly describe the way the environmental impacts are calculated. For each impact category reference is made to literature discussing the scientific background.

\subsubsection{Eco-efficiency indicators for emissions to air and water}

For the impact category climate change, the yearly emissions to air of greenhouse gasses $\mathrm{CO}_{2}, \mathrm{SF}_{6}$, hydrofluorocarbons (HFCs), $\mathrm{N}_{2} \mathrm{O}, \mathrm{CH}_{4}$ and perfluorocarbons (PFCs) are multiplied with the respective Global Warming Potentials (GWP) [10] and added, which results in a total emission in $\mathrm{CO}_{2}$-equivalents.

For the impact category acidification, the yearly emissions of $\mathrm{SO}_{2}, \mathrm{NO}_{\mathrm{X}}$ and $\mathrm{NH}_{3}$ to air are multiplied with their Acidification Potential (AP), resulting in a total emission in $\mathrm{SO}_{2}$-equivalents [11].

The yearly emissions to air of pollutants that contribute to photochemical smog (e.g. $\mathrm{SO}_{2}, \mathrm{NO}_{\mathrm{X}}, \mathrm{CH}_{4}$, volatile organic compounds, ...) are multiplied with the respective Photochemical Ozone Creation Potentials (POCP) and added [12]. The result is a total emission in ethylene equivalents. 
For the calculation of the impact on human toxicity and freshwater aquatic ecotoxicity, the yearly emissions of organic and inorganic toxic components to air and/or water (e.g. polyaromatic hydrocarbons (PAHs), polychlorinated dibenzo-pdioxins and -furans (PCDD/Fs), particulate matter (PM), $\left.\mathrm{SO}_{2}, \mathrm{Cd}, \mathrm{As}, \ldots\right)$ are multiplied with the respective Human Toxicity Potential (HTP) or Freshwater Aquatic Ecotoxicity Potential (FAETP) and added to obtain a total emission in 1,4dichlorobenzene equivalents [13].

The emissions of $\mathrm{NH}_{3}$ and $\mathrm{NO}_{\mathrm{X}}$ (air) and phosphorus and nitrogen containing compounds (water) are multiplied with the respective Eutrophication Potential (EP) and added in order to obtain the total contribution to eutrophication in $\mathrm{PO}_{4}$ equivalents [14].

The eco-efficiency indicators for the different impact categories are obtained by dividing the impact by the relevant economic indicator for the process, company or sector.

\subsubsection{Eco-efficiency indicators for energy consumption and waste generation}

The energy consumption consists of the consumption of energy carriers such as coal, natural gas and electricity for process heat and power applications. The non-energetic energy use i.e. the use of energy carriers as raw materials (e.g. the use of methane for the production of ammonia) is not included. The waste generation consists of the total primary industrial hazardous and non- hazardous waste production. Primary means when a product or byproduct becomes waste for the first time. Secondary waste, produced by the processing of primary waste by recycling and waste treatment 
industries, is not included in the data because otherwise a part of the primary waste would be double counted. As a drawback, the considered amount of waste does not reflect the increasing process efficiency in the recycling and waste treatment industries.

The eco-efficiency indicator for these two themes equals the energy consumption or waste generation, respectively, divided by the relevant economic indicator.

\subsubsection{Eco-efficiency evaluation and decoupling}

The term "decoupling" describes the relation between the trend of environmental impacts on one hand and of the production of economic goods on the other hand, which are supposed to be causally linked [7]. When production increases as a function of time, decoupling occurs when the environmental impact decreases or increases less than the production. In this case the eco-efficiency indicator, which is the ratio of the environmental impact and an economic indicator for production, decreases (eco-efficiency increases). Decoupling is called "relative" if still an increase of the environmental impact is noted, but less than that of the production. Decoupling is called "absolute" if the environmental impact decreases. In order to investigate the trend of an eco-efficiency indicator over a period of time, the value of the indicator at the end of the period is expressed as a percentage of its value at the beginning of the period, which is set equal to 100 . The same is done for the economic indicator. Absolute and relative decoupling is then illustrated by comparing the two percentages.

2.2 Environmental and economic data 
The "Flanders Environment Report" (MIRA) annually describes, analyses and evaluates the state of the environment in Flanders. Furthermore it discusses the conducted environmental policy and focuses on possible new developments. The report is based on a core set of environmental data [8], elaborated by the Flemish Environmental Agency (VMM), including emission data for more than 50 pollutants, organised per sector and sub-sector. In this paper, the method described in the paragraphs 2.1.1 to 2.1.3 is applied to the VMM core set of emission and energy consumption data for the Flemish industrial sector. This sector comprises 6 subsectors: the chemical (NACE-BEL code 24), metal producing and processing (NACE-BEL codes 27 to 35), food (NACE-BEL codes 15 and 16), textile (NACEBEL codes 17 to 19) and pulp-and paper industries (NACE-BEL codes 21 and 22) and some smaller industries such as plastic manufacturing and wood processing (NACE-BEL codes 13, 14, 20, 25, 26, 36, 37, 41 and 45). Mineral oil refining and electricity producing industries are considered a separate sector (energy sector) and the data presented in this paper do not comprise their emissions nor energy consumption. Yet, the emissions from combustion of fuels by the industrial companies are included. VMM collects the emission data through yearly environmental reports, mandatory for companies whose emissions exceed legal threshold values. The additional emissions to air of mainly smaller companies with emissions below the legal threshold are estimated by means of "collective registration", a methodology developed by the Flemish Institute for Technological Research (VITO) [15]. In order to estimate the additional emissions to air due to 
combustion processes, the sectoral energy consumptions derived from the yearly environmental reports are compared with the total sectoral energy consumption as reported in the "Energy Balance for Flanders" [16]. The missing energy consumption per sector is then combined with specific emission factors resulting in the additional emissions from combustion processes. Additional process emissions to air are estimated by multiplying an emission related variable, such as production data (provided by the professional federations or the ministry of economic affairs) with a process related emission factor. For the industrial sector as a whole, the estimated additional emissions account for ca. $10 \%$ of the total emission to air.

The industrial emissions to water are based on emission data from companies directly sampled by VMM. All industrial companies with major emissions to water are included, so the data can be considered representative. The wastewater samples are taken after on-site treatment, if any, but before the water is discharged to surface water or to the public sewerage. In the latter case, the sludge produced in the public wastewater treatment plant is not included in the primary waste considered, but the amounts are considered insignificant.

Since 1995, VMM collects emission data in the way described above. Therefore the trend of the eco-efficiency of the Flemish industry was evaluated from 1995 to 2006, the most recent year for which data were available at the beginning of this study. Yearly, the Flemish Waste Agency (OVAM) estimates the amount of primary industrial waste on the basis of waste reporting by a sample of 15000 companies, using statistical extrapolation methods [17]. The most important industrial waste 
types are mixed and non-differentiated wastes, miscellaneous mineral waste and paper and cardboard [8]. The waste generated by the construction sector is excluded as it varies greatly over the years (e.g. when a motorway is being renewed this generates a substantial amount of waste on a relatively short period of time) and therefore hinders the evaluation of the waste generation by the other industrial subsectors. In 2005 , ca. $10 \%$ of the industrial primary waste consisted of hazardous waste.

The environmental impacts, the energy consumption and waste generation are set equal to 100 for the reference year 1995.

The industrial production index, an index indicating the added value, year to year corrected for price changes, was selected as economic indicator for the calculation of the eco-efficiency indicators. This index, which is an important indicator for the economic situation, is elaborated by the Belgian Directorate-general of Statistics and Economic Information by means of monthly surveys conducted in companies, investigating industrial input (labor, energy, resources, ...) and output (production rates, value of produced goods, ...). It is set equal to 100 for the reference year 1995 and increased by $31 \%$ over the period from 1995 to 2006 [8].

\section{Results and discussion}

The bars in figures 1 to 9 give the eco-efficiency indicators for the Flemish industry relative to the year 1995. The contribution of each pollutant is visualized by different grayscales or textures. The black line in each figure represents the total emission, energy consumption or waste generation (relative to the total emission in 1995, which 
is set equal to 100), without correction for the variation in production (without division by the industrial production index) and is scaled on the right Y-axis. The figures do not give information about the eco-efficiency of the industrial sub-sectors described in paragraph 2.2. However, where possible, this information is given in the discussion of the results in paragraphs 3.1 to 3.8 . Where possible an attempt is made to link the trend of the eco-efficiency indicator to measures imposed by the Flemish government and/or implemented by the industrial companies.

\subsection{Climate change}

The total Flemish industrial greenhouse gas emissions $\left(\mathrm{CO}_{2}\right.$-equivalents $)$ decreased by $20 \%$ between 1995 and 2006 (black line in figure 1). The eco-efficiency indicator for climate change (taking into account the increase in industrial production) decreased by $39 \%$ over the same period, but the decrease seems to slow down the last 5 years. The $\mathrm{SF}_{6}-$, PFC-, and $\mathrm{N}_{2} \mathrm{O}$-emissions decrease more than the $\mathrm{CO}_{2}$-emission, whereas the $\mathrm{CH}_{4}$ - and $\mathrm{HFC}$-emissions increase (not visible in figure 1 due to the small relative contribution). The sudden drop in $\mathrm{SF}_{6}$-emissions between 1996 and 1997 is the result of a modification in the production process at a major chemical company. The chemical and the metal producing and processing industries are the most important sub-sectors with respectively 52 and $26 \%$ of the total industrial greenhouse gas emissions in 2006. In the period 1995 to 2006, the eco-efficiency improved most in the chemical and food industries (both ca. 50\%).

The Flemish "Climate Management Plan" [18] aims to further reduce the industrial greenhouse gas emissions by maximization of energy-efficiency, reduction of $\mathrm{N}_{2} \mathrm{O}$ - 
emissions in the chemical industry, reduction of F-gas emissions and financial support to companies by means of ecological bonuses. If all measures are carried out as planned, the industrial greenhouse gas emissions will be reduced by an extra $10 \%$ by the year 2012. Besides the measures planned by the Flemish government, an increasing number of industrial companies voluntarily take action to reduce their greenhouse gas emission e.g. by means of combined heat and power installations [19].

\subsection{Acidification}

Figure 2 shows that the total emission of acidifying pollutants ( $\mathrm{SO}_{2}$-equivalents) decreased by $42 \%$ in the period 1995 to 2006 . The eco-efficiency indicator for acidification decreased by $55 \%$ over the same period of time. $\mathrm{SO}_{2}$ remains the main contributor, although the $\mathrm{SO}_{2}$-emissions decreased by more than $46 \%$ between 1995 and 2006, mainly due to the increasing use of low sulfur fuels (e.g. natural gas) [19]. The drop of the indicator in 2003 is due to a decrease of $\mathrm{SO}_{2}$-emissions in the ceramic industry. The metal producing and processing and the chemical industry are the main emitters of acidifying gases: in 2006 they contributed to the total industrial acidifying emissions for 30 and $27 \%$, respectively.

The industrial $\mathrm{SO}_{2}$ - and $\mathrm{NO}_{\mathrm{X}}$-emissions partially originate from installations for the production of heat or electricity and do not always directly relate to the processes. In 2004, the European LCP-guideline (2001/80/EG), providing stringent emission standards for burners, was implemented in Flanders. This could explain the decrease of industrial $\mathrm{SO}_{2}$ - and $\mathrm{NO}_{\mathrm{X}}$-emissions over the last two years. Additional emission 
reductions can be expected from process measures such as DeSox- and DeNoxinstallations and higher energy-efficiency [19].

\subsection{Photo-oxidant formation}

Figure 3 shows that the total Flemish industrial emissions of pollutants leading to photochemical smog (ethylene-equivalents) decreased by 23\% between 1995 and 2006. The eco-efficiency indicator for this environmental theme decreased by $41 \%$ over the same period of time. The metal producing and processing industry is the main emitter of photochemical pollutants $(77 \%$ of the total industrial emissions in 2006), mainly CO and xylene-isomers.

As shown in figure 3, NMVOCs (benzene, formaldehyde, tetrachloroethylene, toluene, xylene-isomers) account for $16 \%$ of the total emission of pollutants leading to photochemical smog. The Flemish regulation on environmental permits (VLAREM) implemented the European directive 99/13/EG on the limitation of VOC emissions in 2001, imposing emission limit values for total, conducted and fugitive emissions for solvent based industrial processes. In the chemical industry for example, the reduction of the NMVOC-emissions is the result of process optimisation, the limitation of fugitive emission at storage and transhipment, the use of end-of-pipe technology and, to a lesser extent, the implementation of Leak Detection and Repair (LDAR) programs for fugitive emissions [19].

\subsection{Human toxicity}

The total industrial emission to air and water of toxic substances $(1,4-$ dichlorobenzene equivalents) decreased by 36\% between 1995 and 2006 . 
As shown in figure 4, the total emission of organic substances to the air contributing to human toxicity (1,4-dichlorobenzene equivalents) decreased by $58 \%$ between 1995 and 2001 and slightly increased again afterwards (-33 \% in 2006). The ecoefficiency indicator for human toxicity of organic substances emitted to air, taking into account the increase in production during that period, decreased by $49 \%$. PAH are the main contributors; after 1999 the contribution of the other organic substances including $\mathrm{PCDD} / \mathrm{Fs}$ is negligible. The $\mathrm{PAH}$-emissions are mainly originating from wood preservation. The reduction is most likely the result of the implementation of BAT such as covering of the workspace and installation of closed loop systems [20]. As shown in figure 5, the industrial emissions of heavy metals to air $(1,4-$ dichlorobenzene equivalents) decreased by 58\% between 1995 and 2006. The ecoefficiency indicator for human toxicity due to these emissions decreased by $68 \%$ over the same period of time. The emissions of heavy metals to air only account for $10 \%$ of the total impact in the category human toxicity $(1,4$-dichlorobenzene equivalents). Arsenic, nickel, thallium and vanadium are the main contributors. In 2007, the emissions of nickel and vanadium were relatively low due to productions shifts at two major metal producing companies. The heavy metal emissions originate mainly from the non-ferrous metal industry. Since heavy metals are mostly emitted bound to dust particles, a further reduction of the emissions of particulate matter will also entail a reduction of the emissions of heavy metals [19].

The emission of substances to surface water only accounts for less than $0.1 \%$ of the total impact in the category human toxicity and is not shown. 


\subsection{Freshwater aquatic ecotoxicity}

$80 \%$ of the total freshwater aquatic ecotoxicity of the Flemish industry is due to the emission of heavy metals to air. These emissions decreased by $63 \%$ during the period 1995 to 2006 (figure 6), whereas the eco-efficiency indicator decreased by 72\%. In 2006, vanadium accounted for $86 \%$ of the total impact, nickel for $10 \%$. The decrease of the freshwater aquatic ecotoxicity is also due to the diminishing emission of these two elements. The chemical and the metal producing and processing industry are the main emitters of freshwater aquatic ecotoxic components with 32 and $27 \%$ of the total emission in 2006, respectively.

\subsection{Eutrophication}

Figure 7 shows that the total Flemish industrial emissions to air and water of pollutants leading to eutrophication ( $\mathrm{PO}_{4}$-equivalents) decreased by $38 \%$ between 1995 and 2006. The eco-efficiency indicator for this environmental theme decreased by $53 \%$ over the same period of time. In 2006 , circa $50 \%$ of the eutrophication was due to $\mathrm{NO}_{\mathrm{x}}$-emissions to air; phosphorus and nitrogen containing emissions to water both accounted for ca. $20 \%$. The reduction of total eutrophication is mainly the result of the decrease of phosphorus and nitrogen-containing emissions to water due to improved wastewater treatment by the industrial companies [19]. The chemical and metal producing and processing industries are the main emitters with 35 and $27 \%$ of the industrial emissions leading to eutrophication in 2006, respectively.

\subsection{Energy consumption}


The energy consumption by the Flemish industry increased by $10 \%$ between 1995 and 2006 as the result of the increasing use of solid and liquid fuels, gas and electricity amongst other things due to the commissioning of several new cracking units (Figure 8). From 1999 on, the eco-efficiency indicator for energy consumption started to slightly decrease. In 2006, the energy consumption divided by the production index was $16 \%$ lower than in 1995 . The chemical and metal producing and processing industry are the main energy consumers; they accounted for 39 and $29 \%$ of the total industrial energy consumption in 2006 respectively. The food, chemical and textile industry realised the highest improvement in eco-efficiency (both circa $35 \%)$.

The "Benchmarking-convenant", which started in 2002, is a voluntary agreement between the Flemish government and 178 highly energy intensive companies (yearly energy consumption $>0.5 \mathrm{PJ}$ ), representing circa $80 \%$ of the total industrial energy consumption [21]. It aims at reducing the specific industrial energy consumption by enforcing investments to improve energy efficiency and by the allocation of tradable $\mathrm{CO}_{2}$-emission permits. By 2012 all participating companies should reach the world summit level in energy efficiency, which should result in an energy efficiency improvement of $7.8 \%$ in comparison to 2002 . The Flemish decree on energy planning (may 2004) is another policy instrument to reduce the specific industrial energy consumption in the future [22]. It enforces an energy study for all new or renewed installations with a yearly energy use exceeding 0.1 PJ. This study should prove that 
the installation works at the best economically feasible energy efficiency. These measures should further reduce the industrial energy consumption.

\subsection{Waste generation}

The total Flemish primary industrial waste production (excl. construction waste) increased by $8 \%$ between 1995 and 2005 (figure 9). The eco-efficiency indicator for waste generation, taking into account the increase in industrial production, decreased by $14 \%$ during the same period of time. The waste generated by the construction industry is not taken into account, since it tends to vary greatly over the years and hence hinders the interpretation of the evolution of the other industrial sectors. In 1998, in the food industry, an exceptional high amount of non hazardous waste was generated. The metal producing and processing and the food industry produce most

primary waste: in 2005 they contributed to the total primary industrial waste for $38 \%$ and 34\% respectively. The chemical industry is characterized by the highest ecoefficiency improvement: it produced 46\% less waste per production-index in 2005 in comparison to 1995. The pulp and paper industry, on the other hand, increased its primary waste per production index with $48 \%$ over the same period of time.

\subsection{Improvement of eco-efficiency}

The polygon in figure 10 shows the eco-efficiency indicators for the year 2006 relative to the reference year 1995 for the 8 themes discussed in paragraphs 3.1 to 3.8 . These values are compared to 100 and to the ratio of the production-indices of 1995 (100) and 2006 (131) multiplied by 100, which equals 76. If the eco-efficiency indicator for an environmental theme for 2006 is below 76, the total environmental 
impact for the theme decreased, even though the production index increased. In this case, the decoupling between environmental impact and production is called absolute (light grey area in figure 10). If the eco-efficiency indicator for 2006 lies between 76 and 100, the environmental impact increased, but less than the production index: decoupling is called relative (dark grey area in figure 10). The surface of the light and dark grey area and the area marked by the black line in figure 10 should not be interpreted as a measure of eco-efficiency.

For industrial waste generation and energy consumption, decoupling is relative; for the other 6 themes, it is absolute.

Part of the eco-efficiency improvement could in principle be the result of moving relatively burdensome industrial activities to other regions or countries. In the considered period, only little dislocation of basic industry occurred. Indeed, some major companies in the chemical and metal sector, the two sectors with the highest contribution to the total environmental impact of the industrial sector, have expanded their activities in Flanders over the last decade rather than closing down parts of their production sites. $[23,24]$

\subsection{Environmental profile}

Figure 11 shows the contribution of industry to the 8 discussed environmental themes relative to the total Flemish environmental impact. The industrial contribution to freshwater aquatic ecotoxicity, waste generation, photo-oxidant creation and enegetic energy consumption amounts to $53,51,41$ and $32 \%$, respectively. Despite the improved eco-efficiency, the industry remains one of the main polluters in Flanders. 
Between 1995 and 2006, the contribution of industry decreased for energy consumption, human toxicity, climate change and freshwater aquatic ecotoxicity; for waste generation, photo-oxidant creation, eutrophication and acidification on the other hand, the contribution increased.

\section{Conclusion}

Eco-efficiency indicators have been proven powerful tools in environmental reporting because they link information on environmental impact to economical information in a comprehensive, systematic and consistent manner over periods of time [2,5]. A methodology was proposed introducing eco-efficiency indicators for climate change, acidification, photo-oxidant creation, human toxicity, freshwater aquatic ecotoxicity, eutrophication, energy consumption and waste generation. The method was applied to emission, consumption and production data of the Flemish industrial sector provided by the Flemish environmental agency. For climate change, acidification, photooxidant creation, human toxicity, freshwater aquatic ecotoxicity and eutrophication, the eco-efficiency improved between 1995 and 2006 by 39, 55, 41, 58, 72 and 53\%, respectively. Within each of these impact categories, the total impact decreased even though the production increased, indicating an absolute decoupling of environmental impact and industrial production. Although the eco-efficiency indicators for energy consumption and waste generation improved by respectively 16 and $14 \%$, the total energy consumption and waste generation increased by 10 and $8 \%$, respectively, due to the increase in production between 1995 and 2006: for these two environmental themes decoupling was relative. The Flemish government initiated measures to 
further reduce emissions of mainly greenhouse gases, $\mathrm{SO}_{2}, \mathrm{NO}_{\mathrm{x}}$ and $\mathrm{NMVOC}$ and to decrease energy consumption and waste generation. Despite the improved ecoefficiency, industry remains one of the main polluters in Flanders: the industrial contribution to freshwater aquatic ecotoxicity, waste generation, photo-oxidant creation and energy consumption amounts to $53,51,41$ and $32 \%$ respectively. The application of the proposed method to the core set of emission and consumption data of the Flemish industry results in a comprehensive and correct source of information for the general public and the government. Moreover, it can serve as a basis for economically and environmentally sound decisions and for the evaluation of the impact of former decisions. Application of the method to processes and companies is envisaged as future research.

\section{Acknowledgements}

Marleen Van Steertegem (project leader for MIRA at the Flemish Environmental Agency) is gratefully acknowledged for her constructive remarks. The authors also thank Judith Staginus for processing of the numerous data.

\section{References}

[1] Verfaillie HA, Bidwell R. Measuring eco-efficiency - a guide to reporting company performance. World Business Council for Sustainable Development, 2000

[2] Sturm A, Müller K, Upasena S. A manual for the preparers and users of ecoefficiency indicators. United nations conference on trade and development. Geneva, 2003: UNCTAD/ITE/IPC/2003/7 
[3] National round table on the environment and the economy. Eco-efficiency indicators workbook. Ottawa: Renouf Publishing, 2001

[4] Environmental performance indicators for the chemical industry: The "EPImethod" (version 1.1) - Guideline. Leidschendam: Association of the Dutch Chemical Industry (VNCI), 2001

[5] Van Gerven T., Block C., Geens G., Cornelis C. and Vandecasteele C.

Environmental response indicators for the industrial and energy sector in Flanders. Journal of Cleaner Production 2007; 15 (10): 886-894

[6] Block C., Van Gerven T., Vandecasteele C. Industry and energy sectors in Flanders: environmental performance and response indicators. Clean Technologies and Environmental Policy 2007; 9: 43-51

[7] Indicators to measure decoupling of environmental pressure from economic growth. Organisation of Economic Co-operation and Development (OECD), 2002: SG/SD(2002)1/FINAL

[8] Core set of environmental data MIRA-T 2007 at www.milieurapport.be [9] Flanders in figures 2005 (in Dutch). Ministry of the Flemish Community, 2006. Available at http://aps.vlaanderen.be/statistiek/publicaties/stat Publicaties vic.htm [10] Houghton, JT, Meira Filho LG, Callander BA, Harris N, Kattenberg A, Maskell K (eds). Climate change 1995. The science of climate change; contribution of WGI to the second assessment report of the intergovernmental panel on climate change. Cambridge: Cambridge University Press, 1995. 
[11] Huijbregts MAJ, Schöpp W, Verkuijen E, Heijungs R, Reijnder L. Spatially Explicit Characterization of Acidifying and Eutrophying Air Pollution in Life-Cycle Assessment - Calculation of characterization factors with RAINS-LCA. Journal of Industrial Ecology 2000;4(3):75-93.

[12] Jenkin ME, Hayman GD. Photochemical Ozone Creation Potentials for Oxygenated Volatile Organic Compounds: Sensitivity to Variations in Kinetic and Mechanistic Parameters. Atmospheric Environment 1999;33:1275-1293

[13] Huijbregts MAJ., Thissen ., Guinée JB, Jager T, Kalf D, van de Meent D, Ragas AMJ, Wegener Sleeswijk A, Reijnders L. Priority Assessment of Toxic Substances in Life Cycle Assessment, I: Calculation of Toxicity Potentials for 181 Substances with the Nested Multi-media Fate, Exposure and Effects Model USES-LCA. Chemosphere $2000 ; 41: 541-573$

[14] Guinée BJ, Gorrée M, Heijungs R, Huppes G, Kleijn R, de Koning A, van Oers L, Wegener Sleeswijk A, Suh S, Udo de Haes H.A, de Bruijn H, van Duin R, Huijbregts MAJ. Handbook on Life Cycle Assessment - Operational guide to the ISO standards. Dordrecht: Kluwer Academic Publishers, 2001

[15] Van Rompaey H, Wuyts H. Collective registration of industrial emissions (in Dutch). VITO, 1999 (1999/PPE/R/153)

[16] Aernauts K, Jespers K. Energy balance Flanders 2006: draft June 2008 (in Dutch). VITO, 2008 (2008/IMS/R/)

[17] Claes K, Putseys L, Umans L, De Groof M, Wille D, Vandeputte A, Dons V, Vander Putten E. Environmental Report Flanders MIRA (2007), Background 
document 2007, Management of waste (in Dutch), Flemish Environmental Agency, 2007. Available at www.milieurapport.be

[18] Flemish climate policy plan 2006-2012 (in Dutch). Brussels: Flemish Government - Department Environment, Nature and Energy, 2006. Depotnumber $D \backslash 2006 \backslash 3241 \backslash 277$

[19] Van Caneghem J, Vandecasteele C, Block C, Van Hooste H. Environmental Report Flanders MIRA (2007), Background document 2007, Industry, Flemish Environmental Agency, 2007. Available at www.milieurapport.be [20] Jacobs A, Dijkmans R. Best available techniques for wood preservation (in Dutch). VITO, 1998 (1997/PPE/R/004)

[21] Benchmarking-Convenant on energy-efficiency in industry (in Dutch). Approved by the Flemish government on 29/11/2002. Available at www.benchmarking.be [22] Ministry of the Flemish Community. Decree of the Flemish Government on energy planning for classified energy intensive installations. Approved by the Flemish government on 14/05/2004

[23] ArcelorMittal Gent. Environmental Report 2005-2006. Available at http://www.arcelormittal.com/gent/prg/selfware.pl?id_sitemap $=\&$ language $=\mathrm{EN}$ [24] Essenscia. Facts and Figures. The Chemical and Life Science Industry in Belgium. Issue 2008. Available at http://www.essenscia.be/01/MyDocuments/essenscia_F\&F_2008_HR.pdf 


\section{List of figures}

Figure 1: Evolution of greenhouse gas emissions by the Flemish industry $(1995=$ index 100 , corresponding to 25400 ktonne $\mathrm{CO}_{2}$-equivalents)

Figure 2: Evolution of acidifying emissions by the Flemish industry (1995= index 100, corresponding to 85.4 ktonne $\mathrm{SO}_{2}$-equivalents)

Figure 3: Evolution of photo-oxidant emissions by the Flemish industry (1995= index 100 , corresponding to 12.5 ktonne ethylene-equivalents)

Figure 4: Evolution of human toxic organic emissions to air by the Flemish industry (1995= index 100, corresponding to 25323 ktonne 1,4-dichlorobenzene-equivalents)

Figure 5: Evolution of human toxic heavy metal emissions to air by the Flemish industry (1995= index 100, corresponding to 3837 ktonne 1,4-dichlorobenzeneequivalents)

Figure 6: Evolution of freshwater aquatic toxic heavy metal emissions to air by the Flemish industry $(1995=$ index 100 , corresponding to 267 ktonne 1,4-dichlorobenzeneequivalents)

Figure 7: Evolution of emissions to air and water leading to eutrophication by the Flemish industry (1995= index 100, corresponding to 9.4 ktonne $\mathrm{PO}_{4}$-equivalents) Figure 8: Evolution of the energetic energy consumption by the Flemish industry (1995= index 100, corresponding to $353 \mathrm{PJ})$

Figure 9: Evolution of the waste generated by the Flemish industry $(1995=$ index 100 , corresponding to $7.810^{6}$ tonne) 
Figure 10: Eco-efficiency and decoupling of environmental impact and production in the Flemish industry (impact in 1995=index 100)

Figure 11: Relative contribution (in \%) of the industry to the total environmental impact of Flanders $(=100 \%)$, per theme. 
Figure 1

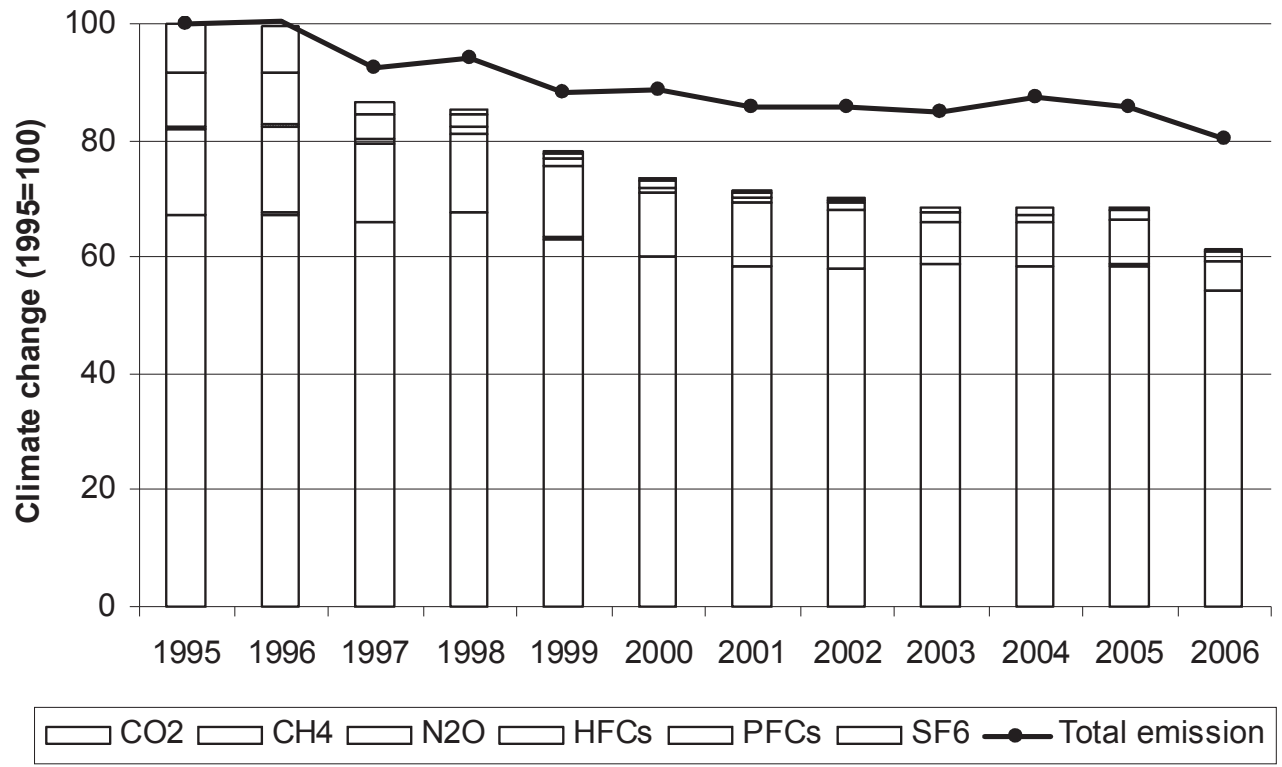


Figure 2

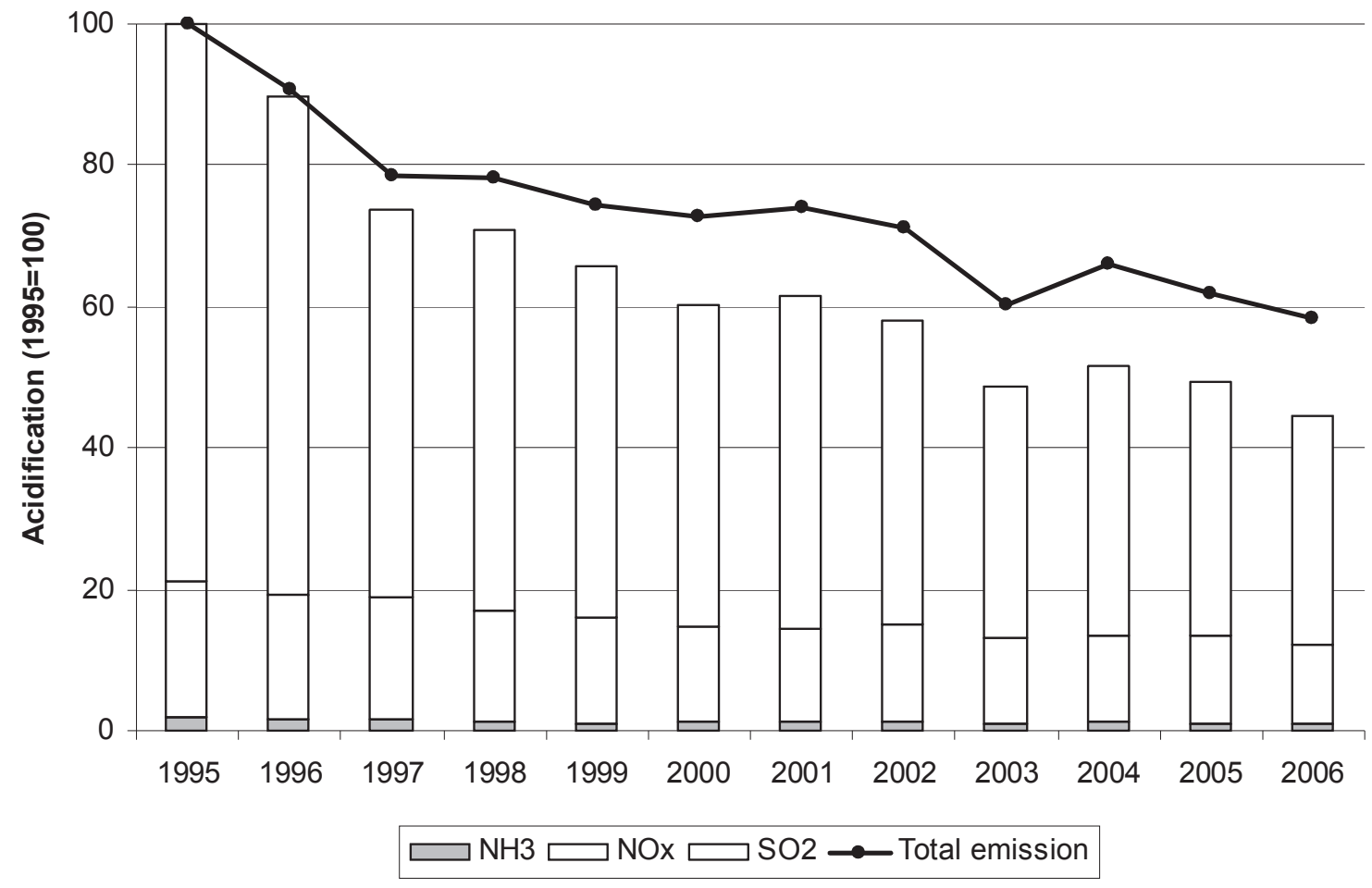


Figure 3

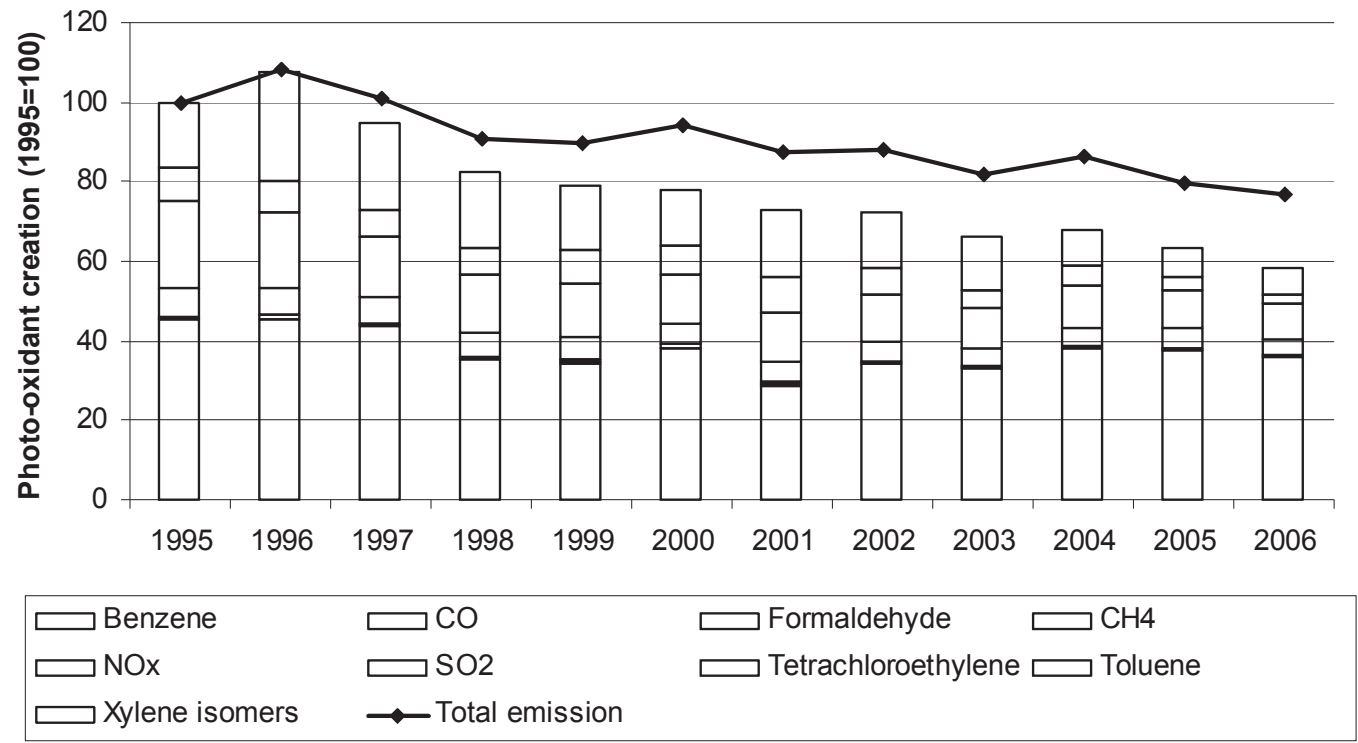


Figure 4

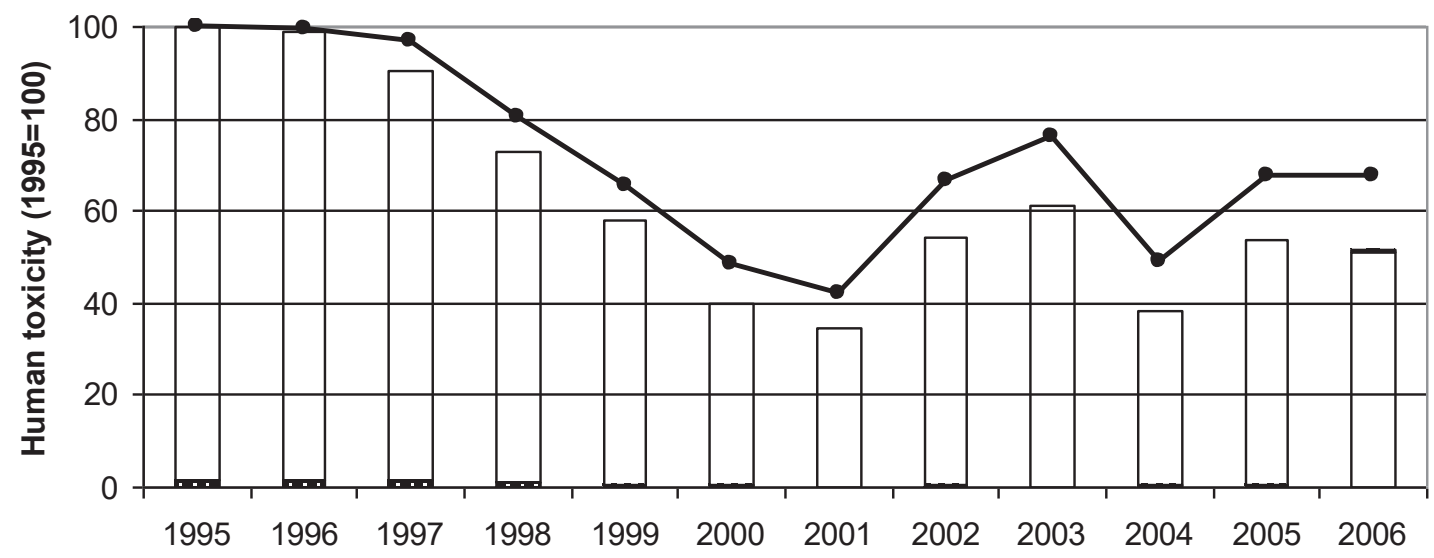

\begin{tabular}{|c|c|c|}
\hline E: 1,2-Dichloroethane & $\therefore 2,3,7,8 \mathrm{TCDD}$ & ¿ Formaldehyde \\
\hline ים" PAH & 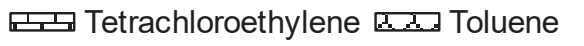 & Vinyl chloride \\
\hline Xylene isomers & $\rightarrow$ Total emission & \\
\hline
\end{tabular}

Xylene isomers $\rightarrow$ Total emission 
Figure 5

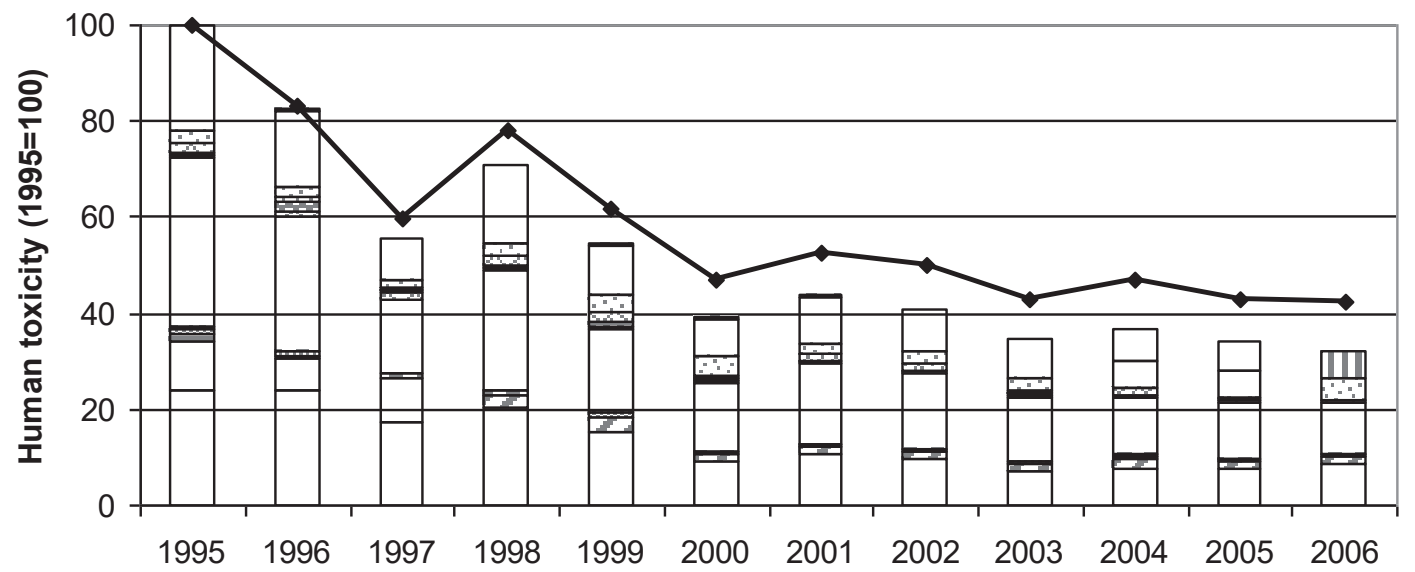

\begin{tabular}{|c|c|c|c|c|}
\hline As & $\because \mathrm{Be}$ & $\approx C d$ & $\rightleftharpoons$ Co & Cr III \\
\hline$\square \mathrm{Cu}$ & $\mathrm{EBg}$ & $\stackrel{\mathrm{Ni}}{\mathrm{m}}$ & $\mathrm{Pb}$ & $\approx \mathrm{Sb}$ \\
\hline $\mathrm{Ex} \mathrm{Se}$ & $\cdots \mathrm{T}$ & एा Va & $\infty \mathrm{Zn}$ & $\smile$ Total emission \\
\hline
\end{tabular}


Figure 6

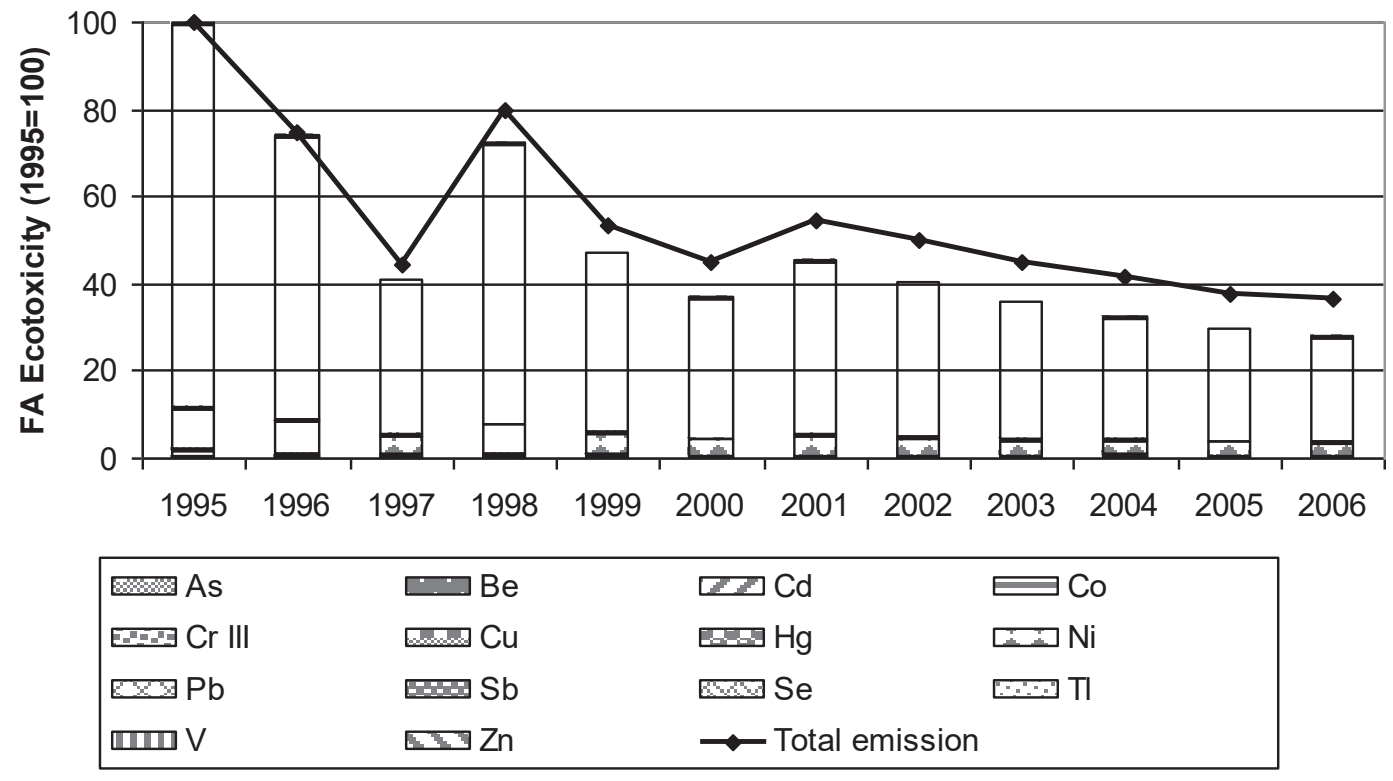


Figure 7

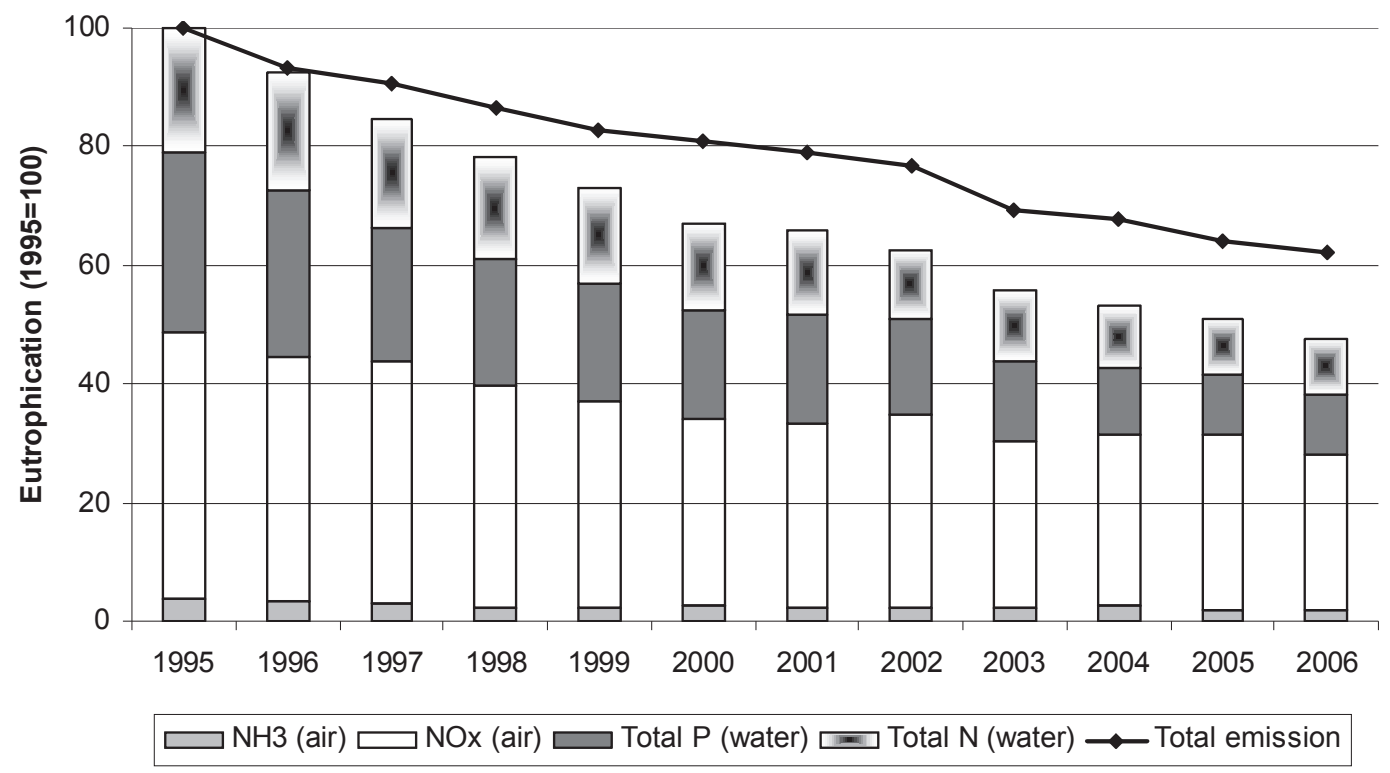


Figure 8

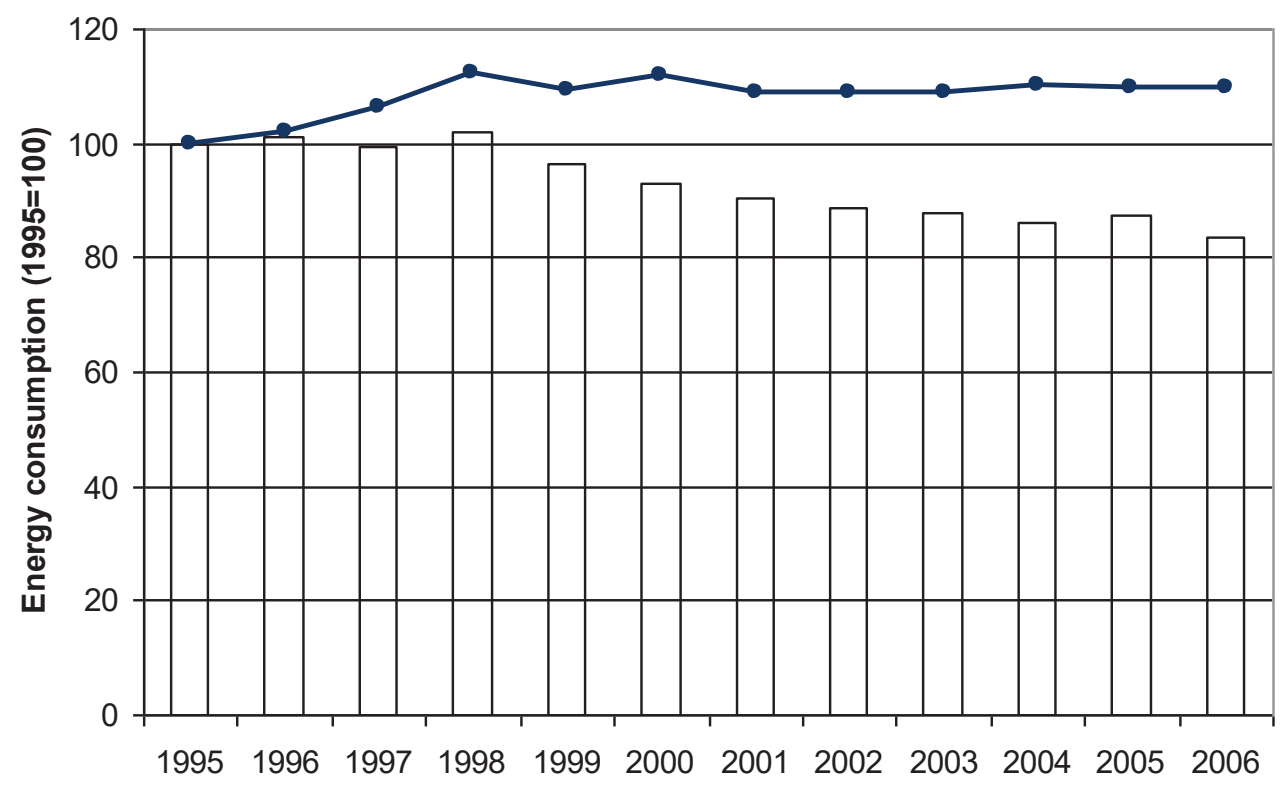

Energy consumption/prod-index $\rightarrow$ Energy consumption 
Figure 9

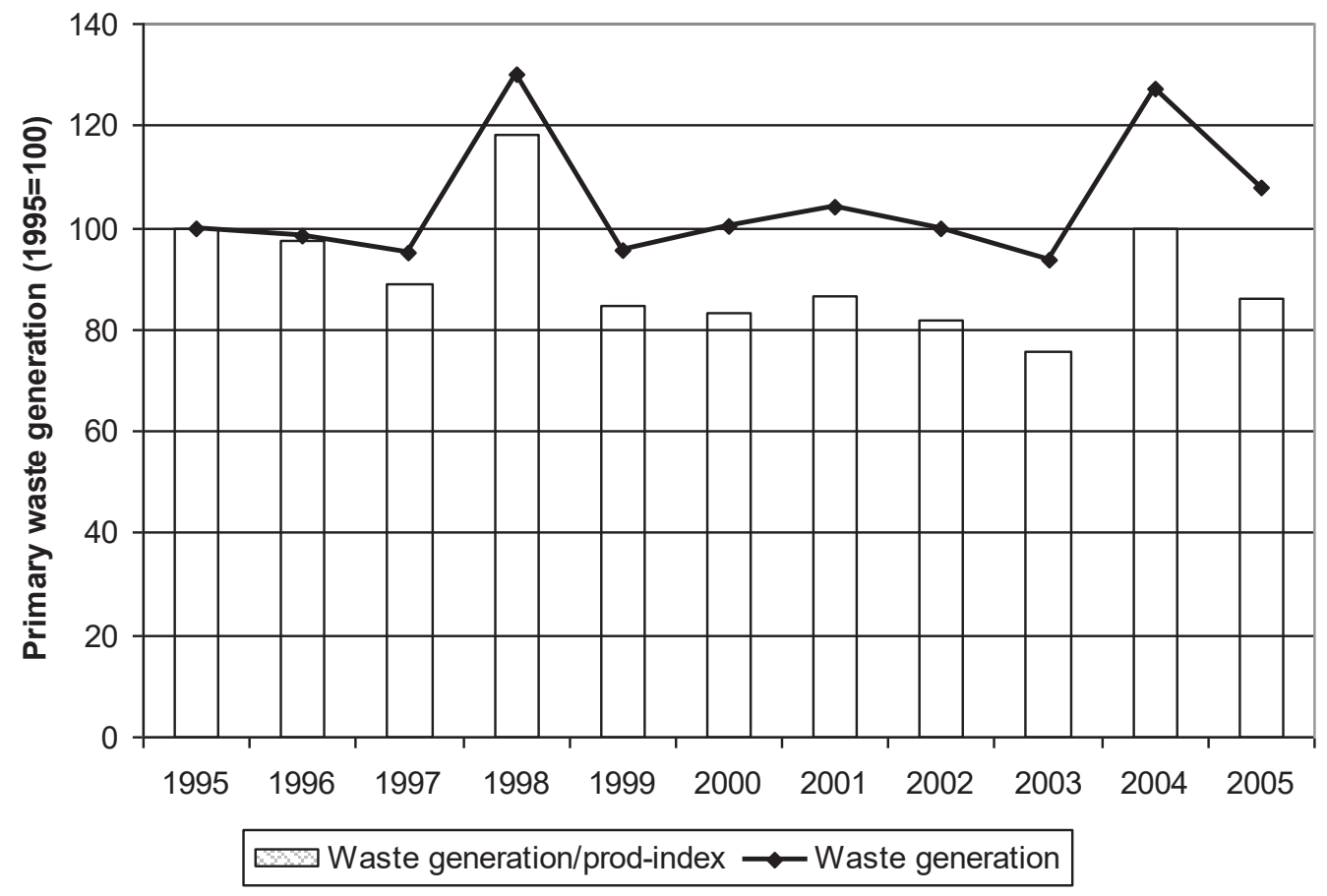




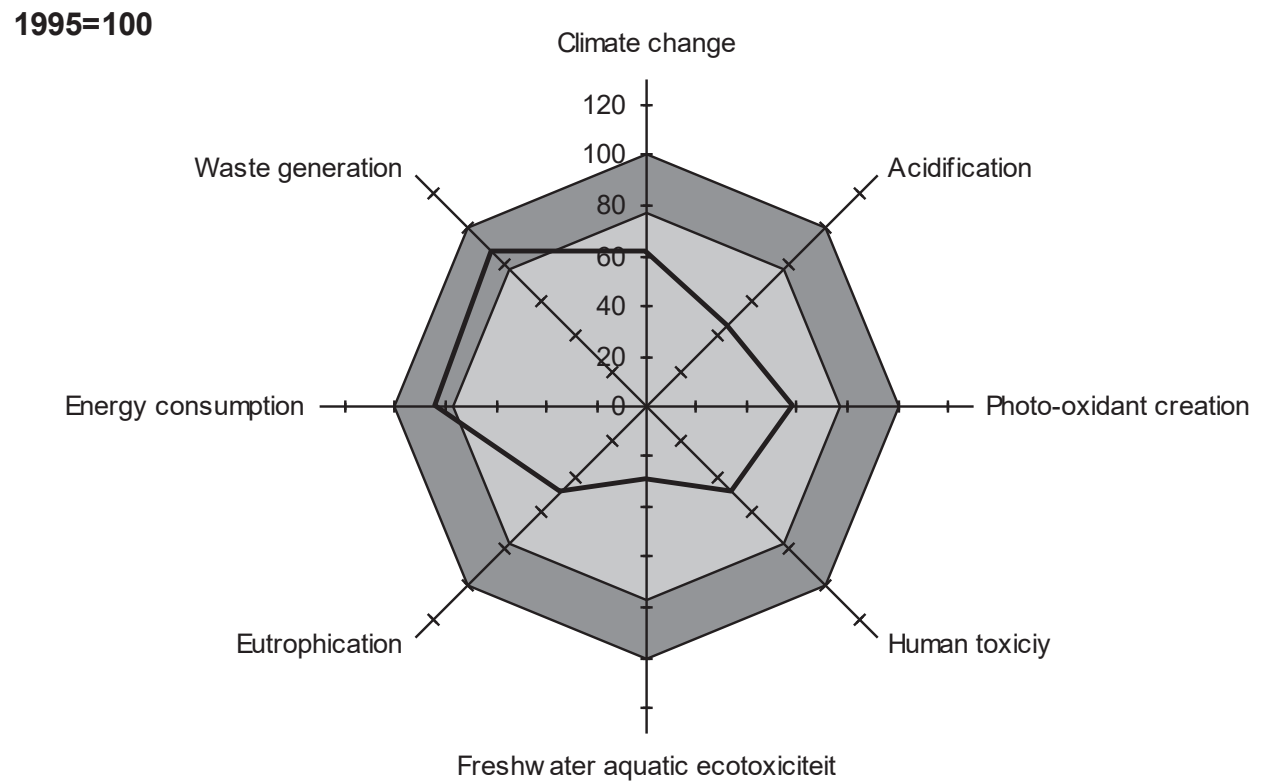

口 Relative decoupling $\square$ Absolute decoupling $\mathbf{2} 2006$ 


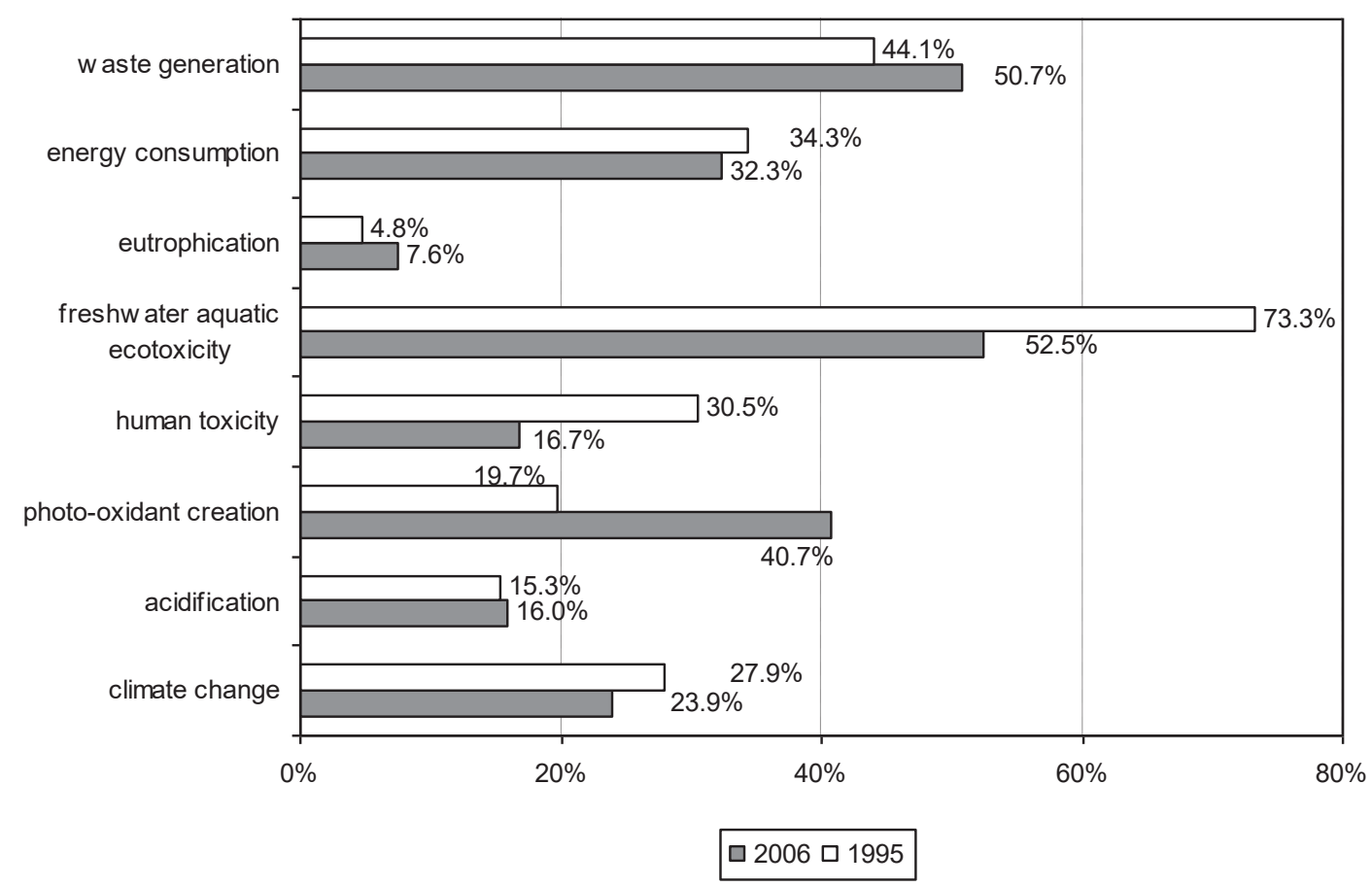

